\title{
A Distributed Architecture of L1 Attrition
}

\author{
Terje Lohndal \\ NTNU Norwegian University of Science and Technology \\ UiT The Arctic University of Norway
}

Hicks \& Domínguez' (2019) keynote paper (henceforth, H\&D) proposes a new model for L1 grammatical attrition called Attrition via Acquisition. An important point of departure is the following paradox: Given that the mechanisms of the Faculty of Language are such that they principally allow for L1 morphosyntax to be modified or lost, why is such modification or loss apparently heavily constrained and seldom attested? (see also Tsimpli 2017: 759). H\&D expand upon a model for L1 acquisition by Lidz \& Gagliardi (2015) and consider how this model can be expanded to also account for the possibility of morphosyntactic attrition. Key ingredients in this model include (i) the distinction between input and intake, (ii) a processing component called the inference engine which consists of the learning mechanisms (including any principles of Universal Grammar) that are used to make inferences about the underlying grammar, and (iii) a particular theory of grammar based on feature assemblies as opposed to parameters.

The goals of the present paper are laudable as they contribute to better integrating multilingual data into formal grammatical models (cf. Benmamoun, Montrul \& Polinsky 2013, Lohndal 2013, Polinsky \& Scontras 2019). That enables us to better model the Faculty of Language in an ecologically valid way, as it moves beyond the monolingual focus that often has characterized formal approaches (see Lohndal, Rothman, Kupisch \& Westergaard in press for more on this). In addition, H\&D's Attrition via Acquisition model also contribute to our understanding of the plasticity of grammar seen through the scarcity of L1 attrition.

H\&D adopt what they label a 'broadly Minimalist model whereby the computational component of the grammar, narrow syntax, builds structure and established syntactic relationships by manipulating the morphosyntactic features bundled onto lexical items'. They argue that the formal model needs to be able to do the following: 1) make specific claims about the structure of the native L1 grammatical competence, and ii) provide a window onto the fine-grained nature of how an 'attrited' grammar may differ from the L1 grammatical competence. The question is to what extent the authors succeed in achieving these two goals. I will discuss both of them focusing on the architecture of the structure of the L1, and on predicting outcomes of attrition.

Given their broad Minimalist orientation, H\&D are understandably not committing themselves to a particular instantiation of a minimalist model. ${ }^{1}$ However, they do appear to be committed to what many would label a 'lexicalist' model of the grammar, that is, a model in which lexical items have features and these features play a crucial role in syntactic derivations. The following quote makes this clear: 'Whereas traditional parameter-based models of grammatical variation fail to provide a natural mechanism for L1 attrition, the feature-based view suggests that, in principle, during a speaker's lifespan his/her grammar may undergo finer-grained changes in morphosyntactic properties, via changes or additions to feature specifications of lexical items' (H\&D). That is, the core explanans in this model are the feature specifications of lexical items.

\footnotetext{
${ }^{1}$ It remains to be worked out what the core desiderata are that one must subscribe to in order to be classified or considered as 'minimalist', a question goes beyond the scope of the current commentary.
} 
Taking a different minimalist perspective, Putnam (2019) suggests that an exponency-based framework may be a better framework, as it offers a theory of how features are lexicalized. I would like to echo this sentiment, but also expand on it. The label 'exoskeletal theory' may be a broader term for frameworks that are considered minimalist in design, in which syntax and morphological realizations are crucially divorced. Well-known implementations of such a theory would be versions of Distributed Morphology (see, among many others, Embick \& Noyer 2007, Embick 2015) and Borer's (2005a, b, 2013) exoskeletal model (see Lohndal to appear for a detailed comparison). The core idea is that features constitute the building blocks of syntactic structures, but that these features subsequently can be realized in a variety of ways post-syntactically. These models crucially also assume that word formation is syntactic, and that word formation in general is governed by syntactic principles. An important consequence in the present context is the question of where grammar change across the lifespan may occur. At least two analytical options are available: Either in the core syntax or in the morphological component of the grammar, broadly speaking. From this perspective, it is an important research question to tease these various analytical possibilities apart, to the extent that this is possible (see Riksem 2018 and Lohndal 2019 for further discussion).

An advantage of the exoskeletal model is that it can account for the fact that structural properties of grammar often remain stable, unlike the morphology (see Polinsky 2018 for a comprehensive review). To capture this, it is advantageous to distinguish between syntax and morphology since a theory with such a distinction predicts that they may develop differentially. The exoskeletal approach is based on such a distinction, capitalizing precisely on the idea that syntactic structure is highly abstract and general, and morphological exponents are inserted post-syntactically. These exponents may also be subject to a range of 'adjustment' procedures, capturing idiosyncratic morphological patterns. Syntax is acquired early, suggesting that the abstract syntactic structures remain quite stable once they have been acquired. Morphology is different, which is also well documented in a range of L2 studies (see Slabakova 2016).

As an example, consider Schmid's (2002) study of language attrition in 54 German Jews who emigrated to England and the US during the second world war. Her material consisted of 5050 sentences which required the subject and the verb to invert, i.e., display Verb Second word order. Importantly, only $102(2 \%)$ did not invert, which is to say that they did not follow the Verb Second rule. This example supports the idea that the syntactic rules are abstract and not related to specific features of lexical items. Rather, the structures constitute a 'template' or a 'skeleton' which can be lexicalized via the insertion of exponents. However, this latter process can be vulnerable and thus subject to attrition.

More generally, a range of other case studies of heritage speakers support the exoskeletal idea that the syntactic structure is abstract and resilient towards change in heritage populations, unlike the morphology, where change easily takes place (e.g., Grimstad, Lohndal and Åfarli (2014), Alexiadou, Lohndal, Åfarli and Grimstad (2015), Grimstad (2018), Riksem (2017, 2018), Alexiadou (2017), and Grimstad, Riksem, Lohndal and Åfarli (2018)). The fact that we see convergence across different areas of attrition can be taken to provide additional support for frameworks that clearly separate syntax and morphological realizations. It seems to me that the Attrition via Acquisition model would be even stronger if couched within such a framework. 
Turning to H\&D's second goal, the issue of predicting outcomes of heritage speakers' grammatical competence has become a central goal in recent research (Polinsky \& Scontras 2019). As Putnam (2019) also points out, H\&D talk about the predictive capabilities of their model but offer little if any proof of concept. Formal models offer a great opportunity for specifying what the possible trajectories may be across different areas of the grammar. Beyond the lack of discussion of cross-linguistic patterns in morphosyntactic attrition, H\&D also do not discuss possible ways of accounting for age effects, e.g., that 'the extent of attrition is inversely related to the age of onset of bilingualism' (Polinsky 2018: 23 and references therein). The majority of work done on L1 attrition has been done with elderly adults (Keijzer 2004, Montrul 2008, Schmid 2011, Polinsky 2018). These speakers had acquired the target grammar before any attrition took place, which sets them aside from other cases of attrition in heritage speakers. H\&D account for why L1 attrition is severely restricted in general, and they point out that their aim is not to offer a 'more detailed set of predictions'. However, they do argue that 'grammatical attrition will consist of adjustments to features on individual morphemes/lexical items of the L1, rather than to broad ranging/typological language 'choices' (H\&D). Again, it seems like an exoskeletal view of the grammar may be ideally suited to work out detailed predictions in future work.

In summary, the Attrition via Acquisition model offers a new and promising framework for the study of L1 attrition and possibly attrition more generally. By articulating an even more detailed formal implementation, the model would be able to move closer to making genuine predictions about cross-linguistic patterns in attrition.

\section{References}

Alexiadou, A. (2017). Building verbs in language mixing varieties. Zeitschrift für Sprachwissenschaft 36: 165-192.

Alexiadou, A, Lohndal, T. Åfarli, T. A., \& Grimstad, M. B. (2015). Language Mixing: A Distributed Morphology Approach. In T. Bui \& D. Özyildiz (eds.), Proceedings of the Fourty-Fifth Annual Meeting of the North East Linguistic Society, 25-38. Create Space.

Benmamoun, E., Montrul, S., \& Polinsky, M. (2013). Heritage languages and their speakers: Opportunities and challenges for linguistics. Theoretical Linguistics 39: 129-181.

Borer, H. (2005a). Structuring Sense, Volume 1: In Name Only. Oxford: Oxford University Press.

Borer, H. (2005b). Structuring Sense, Volume 2: The Normal Course of Events. Oxford: Oxford University Press.

Borer, H. (2013). Structuring Sense, Volume 3: Taking Form. Oxford: Oxford University Press.

Embick, D. (2015). The Morpheme: A Theoretical Introduction. Berlin: Mouton de Gruyter.

Embick, D., \& Noyer, R. (2007). Distributed Morphology and the syntax-morphology interface. In G. Ramchand \& C. Reiss (eds.), The Oxford Handbook of Linguistic Interfaces, 289-324. Oxford: Oxford University Press. 
Grimstad, M. B. 2018. English-origin verbs in American Norwegian. Doctoral dissertation, NTNU Norwegian University of Science and Technology.

Grimstad, M. B., Lohndal, T., \& Åfarli, T. A. (2014). Language mixing and exoskeletal theory: A case study of word-internal mixing in American Norwegian. Nordlyd 41: 213-237.

Grimstad, M. B. Riksem, B. R., Lohndal, T., \& Åfarli, T. A. (2018). Lexicalist vs. exoskeletal approaches to language mixing. The Linguistic Review 35: 187-218.

Hicks, G., \& Domínguez, L. (2019). A model for L1 grammatical attrition. Second Language Research.

Keijzer, M. (2004). First language attrition: A cross-linguistic investigation of Jakobson's regression hypothesis. International Journal of Bilingualism 8: 389-393.

Lidz, J., \& Galiardi, A. (2015). How nature meets nurture: Universal Grammar and statistical learning. Annual Review of Linguistics 1(1), 333-352.

Lohndal, T. (2013). Generative grammar and language mixing. Theoretical Linguistics 39: 215-224.

Lohndal, T. (2019). Predicting outcomes in heritage grammars. Bilingualism: Language and Cognition 1-2. DOI: 10.1017/S1366728919000403

Lohndal, T. (to appear). The exoskeletal model. In A. Alexiadou, R. Kramer, A. Marantz \& I. Oltra-Massuet (eds.), The Cambridge Handbook of Distributed Morphology. Cambridge: Cambridge University Press.

Lohndal, T., Rothman, J., Kupisch, T., \& Westergaard, M. (In press). Heritage Language Acquisition: What it Reveals and Why it is Important for Formal Linguistic Theories. Language and Linguistics Compass.

Montrul, S. (2008). Incomplete Acquisition in Bilingualism: Re-examining the Age Factor. Amsterdam: John Benjamins.

Polinsky, M. (2018). Heritage languages and their speakers. Cambridge: Cambridge University Press.

Polinsky, M., \& Scontras, G. (2019). Understanding heritage languages. Bilingualism: Language and Cognition, 1-17. https://doi.org/10.1017/S1366728919000245

Putnam, M. (2019). Lexicalizing exponents in multilingual grammars. Second Language Research.

Riksem, B. R. 2017. Language Mixing and Diachronic Change: American Norwegian Noun Phrases Then and Now. Languages 2, 3, doi: 10.3390/languages2020003

Riksem, B. R. 2018. Language mixing in American Norwegian noun phrases. Doctoral dissertation, NTNU Norwegian University of Science and Technology. 
Riksem, B. R., Grimstad, M. B., Lohndal, T., \& Åfarli, T. A. (2019). Language mixing within verbs and nouns in American Norwegian. Journal of Comparative Germanic Linguistics 22: 189-209.

Schmid, M. (2002). First Language Attrition, Use and Maintenance. Amsterdam: John Benjamins.

Schmid, M. (2011). Language Attrition. Cambridge: Cambridge University Press.

Slabakova, R. (2016). Second Language Acquisition. Oxford: Oxford University Press.

Tsimpli, I. M. (2017). Crosslinguistic influence is not necessarily attrition. Linguistic Approaches to Bilingualism 7: 575-762. 